\title{
Relationships of physiologically equivalent temperature and hospital admissions due to I30-I51 other forms of heart disease in Germany in 2009-2011
}

\author{
Ivy Shiue $^{1,2} \cdot$ David R. Perkins ${ }^{3} \cdot$ Nick Bearman $^{4}$ \\ Received: 14 March 2015 / Accepted: 3 November 2015 / Published online: 1 December 2015 \\ (C) The Author(s) 2015. This article is published with open access at Springerlink.com
}

\begin{abstract}
We aimed to understand relationships of the weather as biometeorological and hospital admissions due to other forms of heart disease by subtypes, which have been paid less attention, in a national setting in recent years. This is an ecological study. Ten percent of daily hospital admissions of the included hospitals $(n=1618)$ across Germany that were available between 1 January 2009 and 31 December $2011(n=5$, 235,600) were extracted from Statistisches Bundesamt, Germany. We identified I30-I51 other forms of heart disease by the International Classification of Diseases version 10 as the study outcomes. Daily weather data from 64 weather stations that have covered 13 German states, including air temperature, humidity, wind speed, cloud cover, radiation flux and vapour pressure, were obtained and generated into physiologically equivalent temperature (PET). Admissions due to other diseases of pericardium, nonrheumatic mitral valve disorders, nonrheumatic aortic valve disorders, cardiomyopathy, atrioventricular and left bundle-branch block, other conduction disorders, atrial fibrillation and flutter, and other cardiac arrhythmias peaked when PET was between 0 and $10{ }^{\circ} \mathrm{C}$.
\end{abstract}

Responsible editor: Philippe Garrigues

Ivy Shiue

ivy.shiue@northumbria.ac.uk

1 Faculty of Health and Life Sciences, Northumbria University, Newcastle upon Tyne NE1 8ST, England, UK

2 Owens Institute of Behavioral Research, University of Georgia, Athens, GA, USA

3 Center for Climate Change Communication, George Mason University, Fairfax, VA, USA

4 School of Environmental Sciences, University of Liverpool, Liverpool, England, UK
Complications and ill-defined descriptions of heart disease admissions peaked at PET $0{ }^{\circ} \mathrm{C}$. Cardiac arrest and heart failure admissions peaked when PET was between 0 and $-10{ }^{\circ} \mathrm{C}$ while the rest did not vary significantly. A common drop of admissions was found when PET was above $10{ }^{\circ} \mathrm{C}$. More medical resources could have been needed for heart health on days when PETs were $<10{ }^{\circ} \mathrm{C}$ than on other days. Adaptation to such weather change for medical professionals and the general public would seem to be imperative.

Keywords Weather · Heart - Pericarditis - Cardiac arrest . Heart failure $\cdot$ Atrial fibrillation

\section{Introduction}

\section{Evidence before this study}

Environmental factors have been central to many human chronic diseases, and the weather is no exception. The effect of the weather has been noted in scientific literature since the 1930s as increased hospital admissions due to coronary occlusion and heart failure were observed in correlation with low temperature that has prompted the concern on the influence of the seasonality effect (Bean and Mills 1938). The hypothesized mechanism was that an acute change in environmental temperature, being too cold or too hot (Bhaskaran et al. 2009), tends to increase myocardial oxygen consumption and may induce cardiac arrhythmias or an anginal attack (Ansari and Burch 1969; Epstein et al. 1969; Milo-Cotter et al. 2006). In addition, activation of the sympathetic nervous system and secretion of catecholamine could increase in response to low temperature that could be observed by the increased heart rate and peripheral vascular resistance (Hanna 1999). However, overall across the globe, conflicting results on the effect of 
the weather on human health outcomes have been presented in the literature.

\section{Knowledge gap}

While there are complex interactions between the weather and human health outcomes that have been observed, methodological concerns on the risk assessment from previous research have been brought up recently (Modesti 2013). Seemingly, correlating air temperature and human health outcomes might not be adequate since there has been a difference between air temperature and the weather as biometeorological incorporating relevant meteorological parameters (Shiue and Matzarakis 2011). In addition, all the meteorological parameters are interacting with each other at the same time. Therefore, it would make no environmental or meteorological sense to only include air temperature or treat other climatic variables separately as the exposure. Since less attention has been paid to other forms of heart disease, compared to commonly known heart disease and cardiovascular disease, the present study would contribute to the scientific community with such evidence.

\section{Study aim}

Following this context, we aimed to firstly investigate the monthly variations of hospital admissions due to other forms of heart disease and then to correlate with the weather as biometeorological in a national setting in recent years.

\section{Methods}

\section{Study exposures and outcomes}

This is an ecological study. Daily historical meteorological data including air temperature, humidity, wind speed, radiation flux, cloud cover and vapour pressure between 1 January 2009 and 31 December 2011 (three full calendar years) were obtained from the Federal Ministry of Transport, Building, and Urban Development (more details via http://www.dwd. de/). Daily hospital admissions with all diagnoses including emergency admissions in the same study period were extracted from the database held in Statistisches Bundesamt (more details via https://www.destatis.de/EN/Homepage. html), Wiesbaden, Germany. Statistisches Bundesamt randomly selects $10 \%$ of hospital admissions (including first occurrence and recurrence) of each German hospital at the end of each year and stores the data for research purposes. Currently, there are 1618 hospitals in their record list. The admission ('primary diagnosis') is coded using the International Classification of Diseases version 10 codes (WHO 2009). In this study, we identified hospital admissions due to I30-I51 other forms of heart disease by subtypes (see Table 1) as the study outcomes, which were commonly seen in society, had enough number of events to be examined statistically and would protect any individual's identity due to small numbers.

\section{PET calculation}

In the first phase, to handle study exposures, we firstly used a geographic information system to map out the included weather stations (64 out of 78 representative stations across Germany based on the completeness of meteorological data) from each state of Germany. There are 16 states in total. For each of the included weather stations (see black dots shown in Fig. 1) in each German state, we generated all the included meteorological parameters mentioned above into a single index called physiologically equivalent temperature (PET) as the main study exposure to be correlated with hospital admissions. We then averaged daily PETs from each weather station for each German state. PET, with the widely known unit degrees Celsius, has been known to be used when considering the heat balance of the human body under standard conditions in an outdoor setting and initially created to characterize and evaluate the human bioclimate in a physiological setting (Höppe 1999). PET takes into consideration thermoregulatory processes such as sweat rate and blood vessel dilation and allows the user of the model to predict thermal attributes of the body such as sweat rate, core temperature and skin temperature. Calculating PET requires atmospheric, geographical and human-physiological inputs. In our case, we used the RayMan software for calculation (more details via http:// www.mif.uni-freiburg.de/rayman/intro.htm). Atmospheric inputs include temperature, wind speed, humidity, sky cover and solar radiation. Geographical inputs include altitude and day length (assessed through latitude and longitude). Physiological inputs include gender, age, height, weight, amount of clothing and activity levels (measured in watts). Clothing values are seasonally adjusted for summer, winter and shoulder seasons, and all other physiological inputs are held constant based upon default model parameters. In the current analysis, 64 weather stations from 13 states with complete weather data were included for the statistical analysis. This has excluded three states containing Berlin, Saarland and Saxony-Anhalt without any of the meteorological parameters that would be needed for PET calculation.

\section{Statistical analysis}

During the second phase, we plotted two-way fractionalpolynomial prediction plots with confidence intervals (CI) in order to better describe the potential non-linear relationships between the weather and hospital 


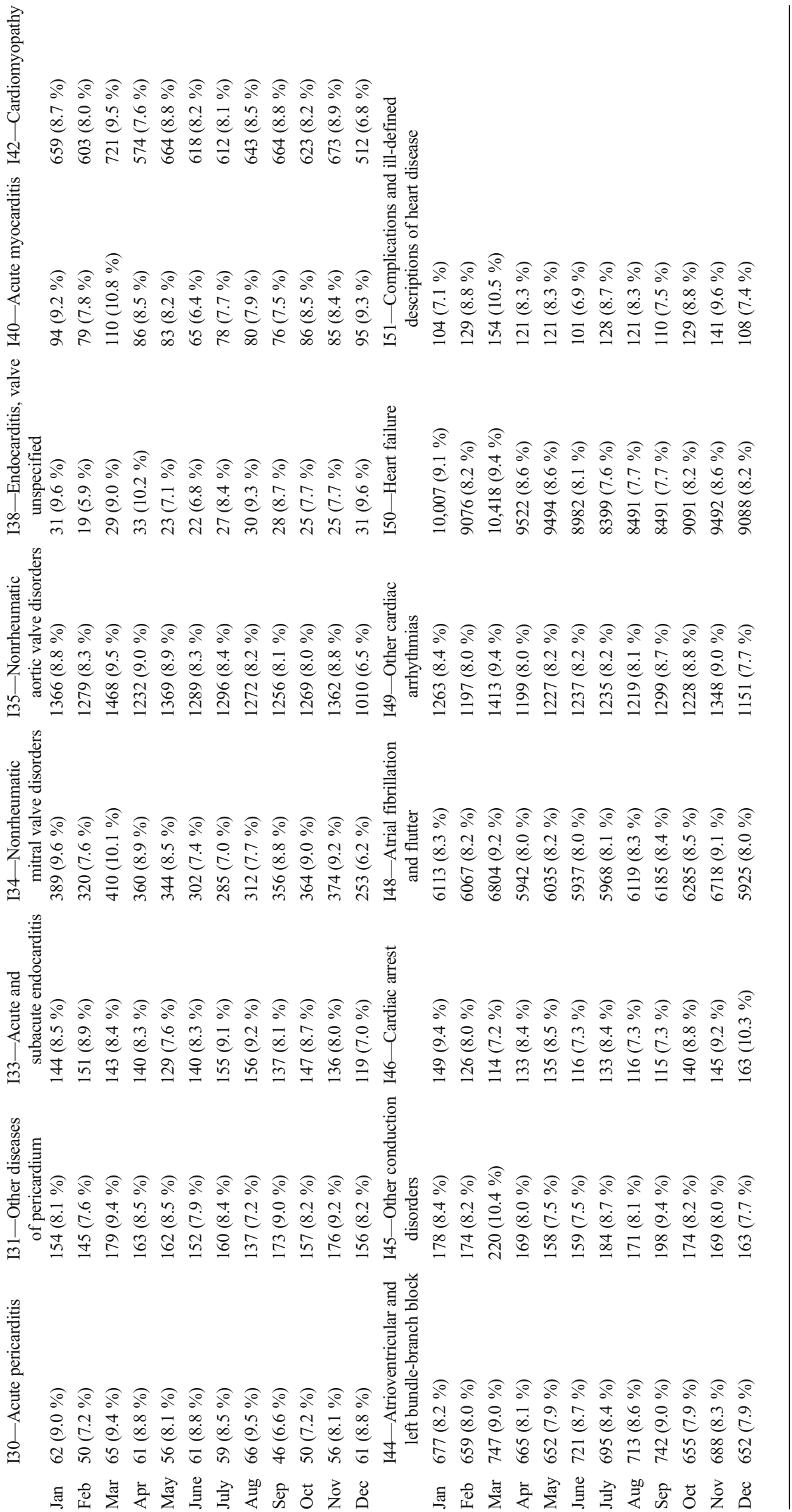


Fig. 1 The included weather stations in Germany

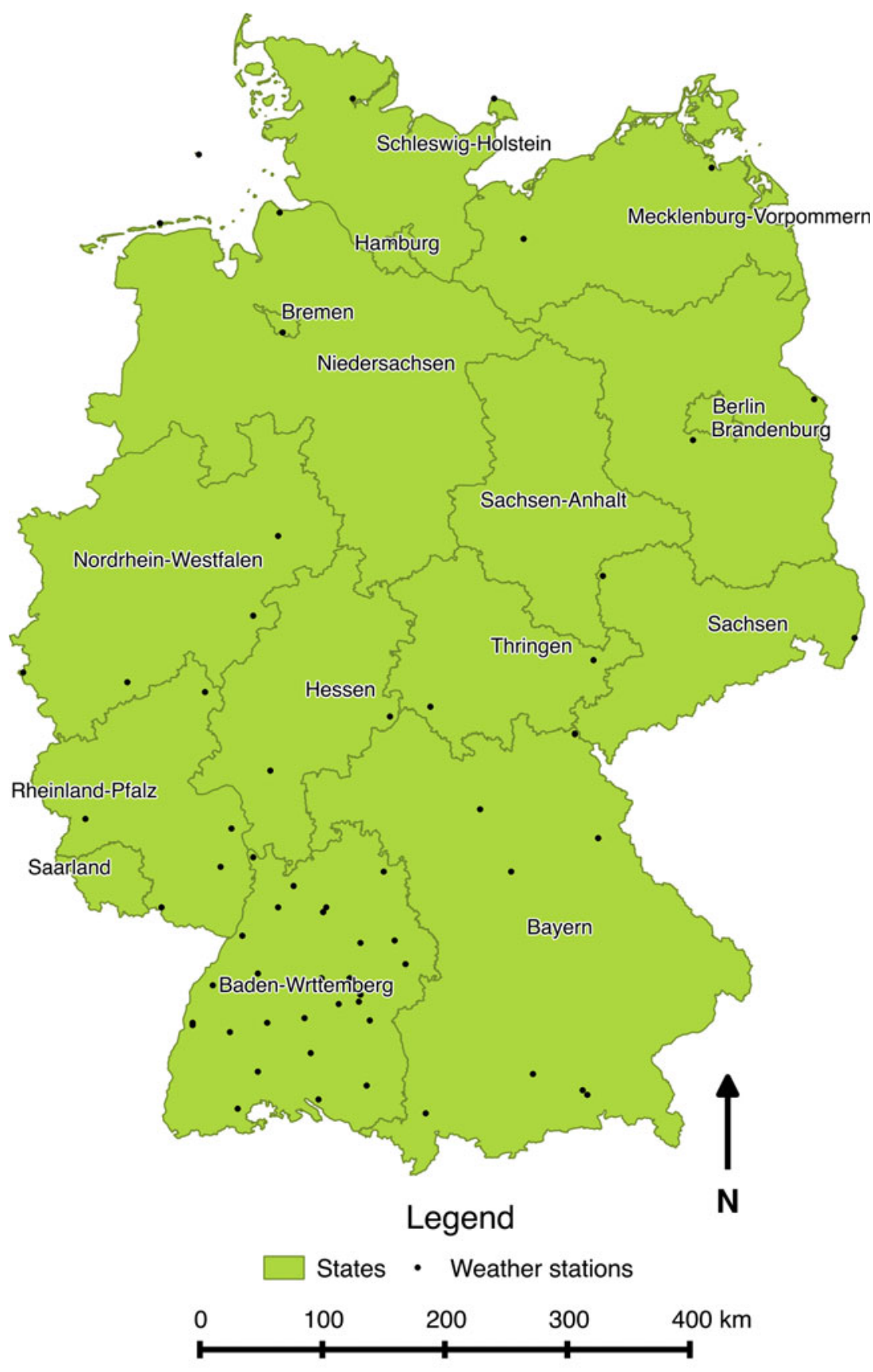

Created August 2014 using boundary data from http://www.gadm.org admissions (the $y$ axis in each figure denotes log-hazard ratios). Due to the German law prohibiting reporting of individual admissions and hospitals, correlational analysis was only made on a daily basis but not hourly. From the generated PETs in 2009-2011 (see Fig. 2), it was observed that there was no heat stress $\left(\mathrm{PET}>35{ }^{\circ} \mathrm{C}\right.$ in Western Europe; Matzarakis and Mayer 1996). PETs were mainly between -10 and $20{ }^{\circ} \mathrm{C}$ throughout 3 years in 2009-2011. Statistical software STATA 12.0 version
(STATA, College Station, TX, USA) was used to perform all the statistical analyses.

\section{Ethics approval and funding}

This study was approved and supported by the EU FP-7 Data without Boundaries project (grant number 262608; more details via http://www.dwbproject.org/) and Statistisches 


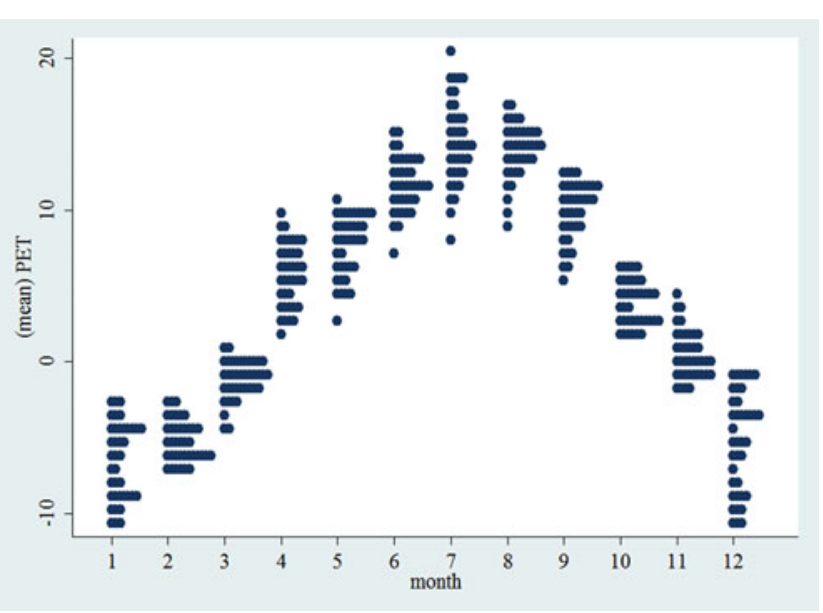

Fig. 2 Averaged PET by month and by day over 3 years in 2009-2011

Bundesamt, Germany. Since this study is only a secondary data analysis, no other ethics approval was required.

\section{Results}

Table 1 shows the monthly number of hospital admissions due to some common other forms of heart disease by subtypes. In general, for some subtypes, admissions peaked in winter and spring while the others did not seem to vary significantly. In Figs. 3, 4, 5, 6, 7, 8, 9, 10, 11, 12, 13, 14, 15, 16 and 17, the relationships of PETs and hospital admissions due to other forms of heart disease by subtypes are displayed accordingly. There could be four groups of phenomenon among these admissions. To be specific, admissions due to other diseases of pericardium, nonrheumatic mitral valve disorders, nonrheumatic aortic valve disorders, cardiomyopathy, atrioventricular and left bundle-branch block, other conduction

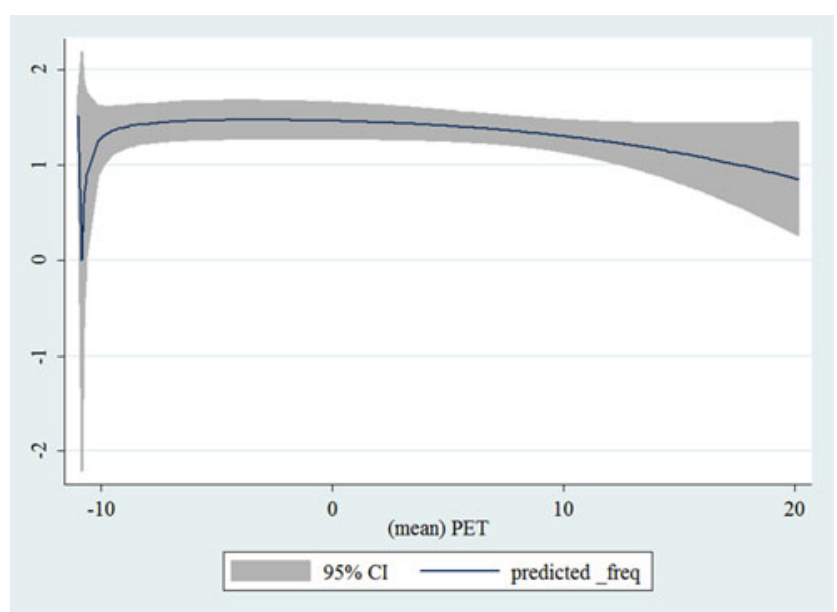

Fig. 3 Relationship of PETs and admissions of I30-Acute pericarditis

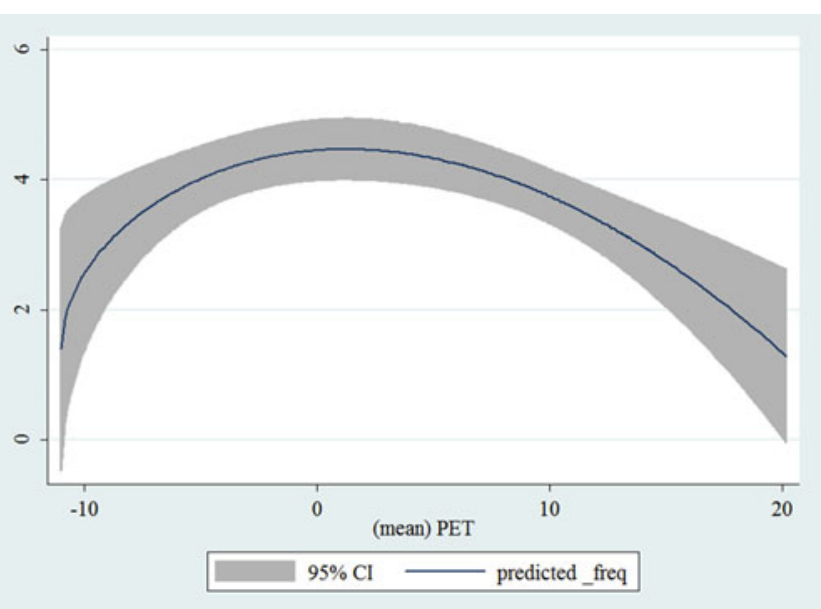

Fig. 4 Relationship of PETs and admissions of I31-Other diseases of pericardium

disorders, atrial fibrillation and flutter, and other cardiac arrhythmias peaked when PET was between 0 and $10{ }^{\circ} \mathrm{C}$. Complications and ill-defined descriptions of heart disease admissions peaked at PET $0{ }^{\circ} \mathrm{C}$. Cardiac arrest and heart failure admissions peaked when PET was between 0 and $-10{ }^{\circ} \mathrm{C}$ while the rest did not vary significantly. A common drop of admissions was found when PET was above $10{ }^{\circ} \mathrm{C}$.

\section{Discussion}

There has been only very few literature on the relationships between the weather and other forms of heart disease. In spite of relatively fewer admissions recorded in the population, the other reason might be the low variation of hospital admissions across seasons. Of note, we noted scientific literature on admissions, incidence or prevalence of human diseases but not

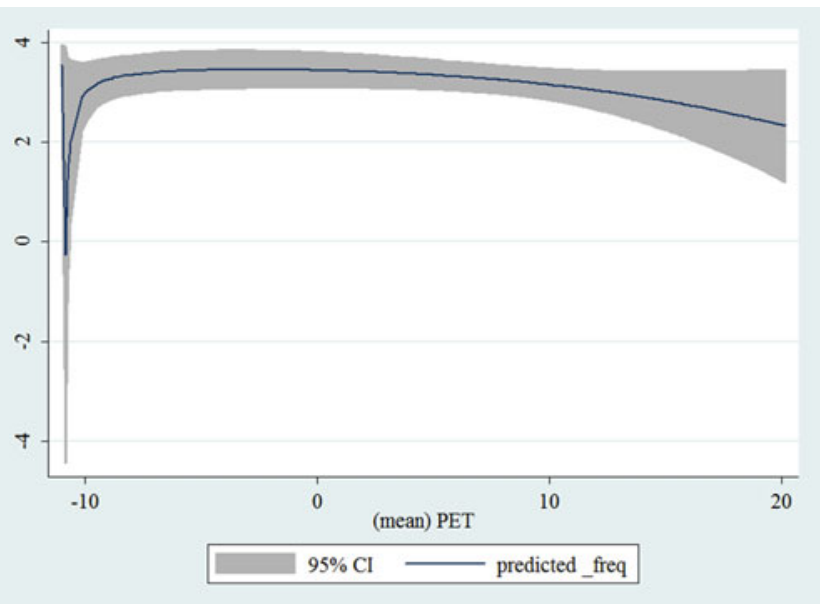

Fig. 5 Relationship of PETs and admissions of I33 - Acute and subacute endocarditis 


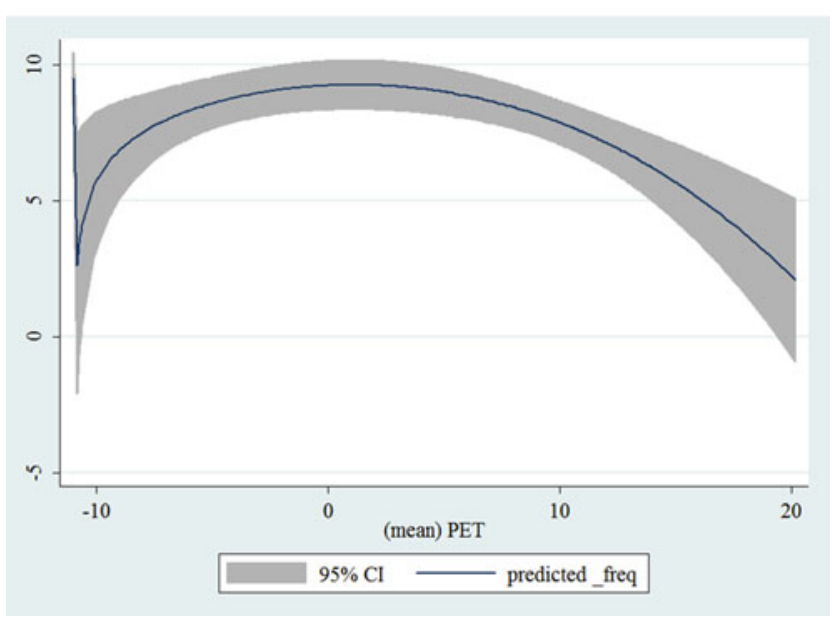

Fig. 6 Relationship of PETs and admissions of I34-Nonrheumatic mitral valve disorders

death/mortality alone. This is because disease severity and treatment efficacy would be more important than the weather in relation to disease mortality as patients would have stayed in hospital during this period. Future research, either observational or experimental, looking into this topic should be encouraged.

\section{Weather and endocarditis}

Back in the 1960s, animal research already observed the effect of exposure and acclimatization to cold on susceptibility of rats to bacterial endocarditis (Highman and Altland 1962). In a single hospital in Cleveland, USA, in 1993-2001 (Finkelhor et al. 2005), a study with a slightly larger human sample $(n=1279)$ found more admissions in the cold months as well. In a single hospital in Taipei, Taiwan, in 2003-2009 (Chen et al. 2012), cool

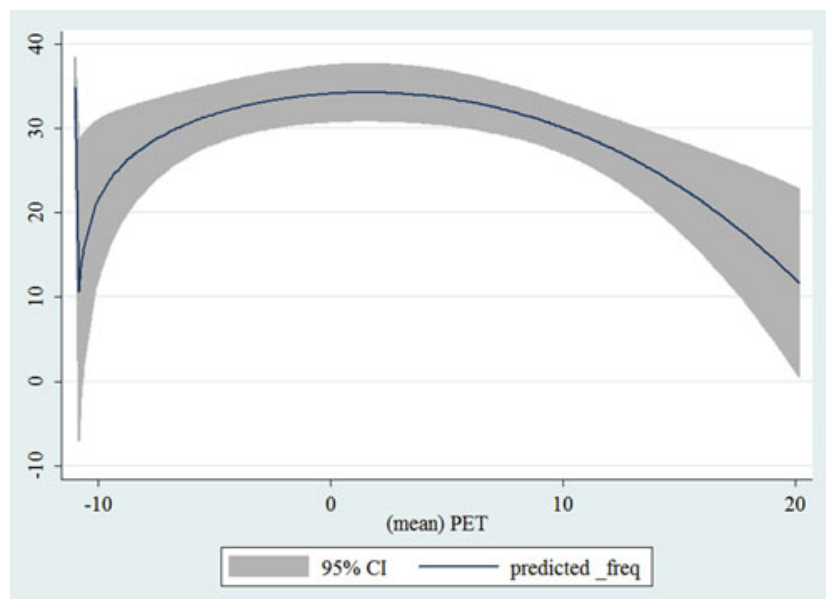

Fig. 7 Relationship of PETs and admissions of I35-Nonrheumatic aortic valve disorders

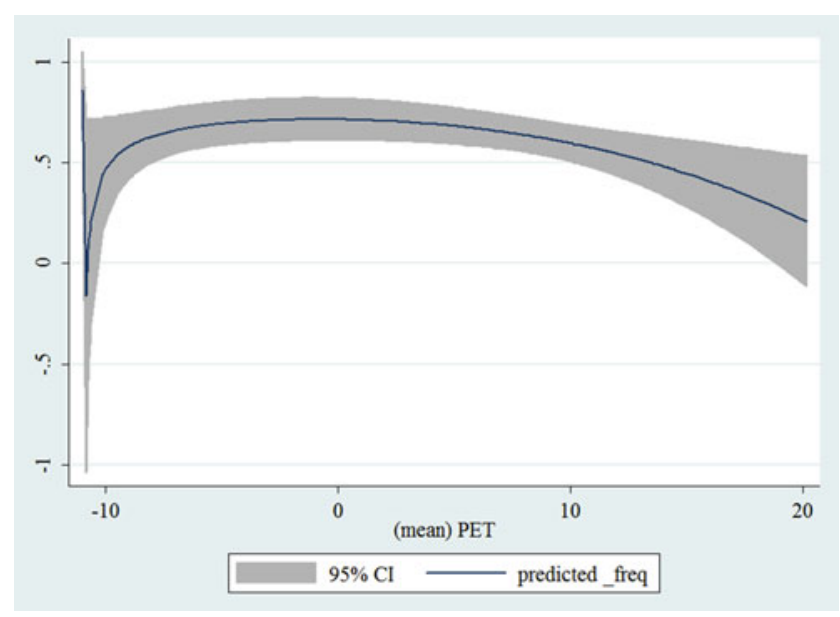

Fig. 8 Relationship of PETs and admissions of I38 - Endocarditis, valve unspecified

seasons (temperature was averaged monthly) were observed to be associated with poor prognosis in human patients with infective endocarditis, although the sample size was rather small $(n=100)$. For some forms of heart disease such as myocarditis, fever that could occur more on the cold days or during the change of weather might explain some the peaks of hospital admissions.

\section{Weather and atrioventricular block}

Literature on the relationship of the weather and atrioventricular block is much scarce. In a single hospital in Taipei, Taiwan, in 2004-2008 (Liu et al. 2011), a temperature (air temperature) change of greater than $11{ }^{\circ} \mathrm{C}$ within 30 days prior to admission was associated with a significantly higher proportion of patients with advanced atrioventricular block.

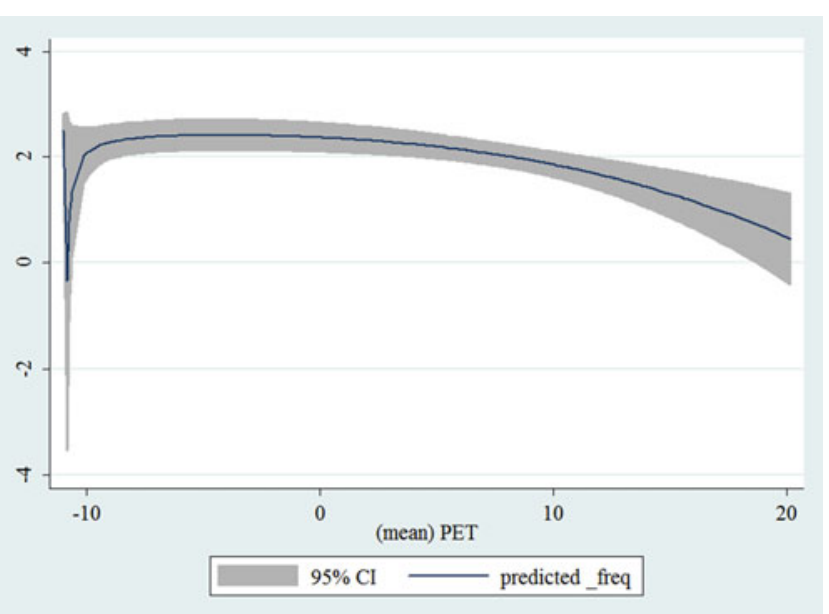

Fig. 9 Relationship of PETs and admissions of I40 - Acute myocarditis 


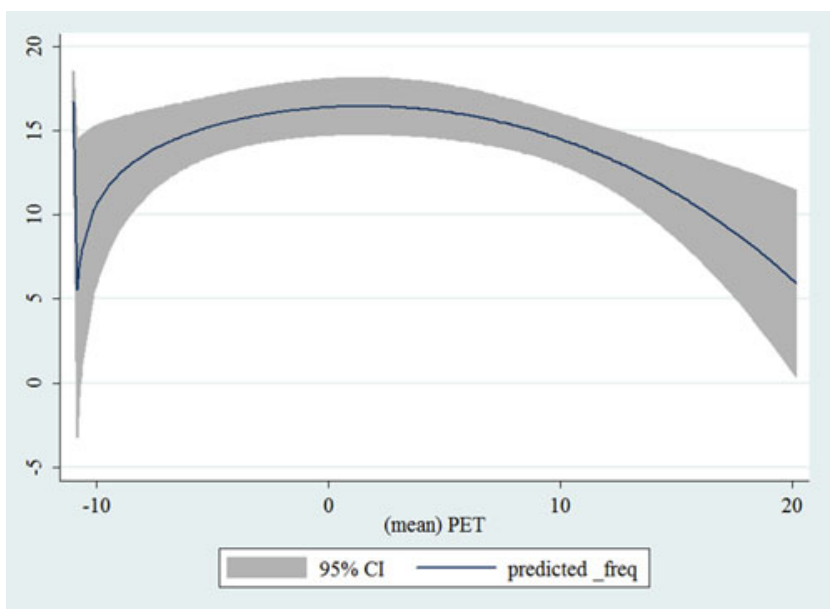

Fig. 10 Relationship of PETs and admissions of I42 - Cardiomyopathy

\section{Weather and cardiac arrest/arrhythmias}

Although there seems to be more literature on the relationship of the weather and cardiac arrest, it was mostly focusing on out-of-hospital events, mortality or neurological conditions after cardiac arrest events. In Osaka, Japan, in 1998-2007 (Tanigawa-Sugihara et al. 2013), the number of out-ofhospital cardiac arrest events in 1 day was inversely correlated with the day's mean atmospheric temperature, and the regression coefficient was greater on the days under $18{ }^{\circ} \mathrm{C}(r=$ $-0.317, P<0.001)$ than on days over $18{ }^{\circ} \mathrm{C}(r=-0.088, P<$ 0.001). In a single hospital in Vienna, Austria, in 1991-2010 (Stratil et al. 2013), nearly half of cardiac arrest patients were admitted to the hospital when the air temperature (meteorological data from four close weather stations) was $<10{ }^{\circ} \mathrm{C}$. In Sweden in 1990-1999 (Herlitz et al. 2002), admissions of cardiac arrest were observed to occur more in December and January when the cold months start. Literature on the

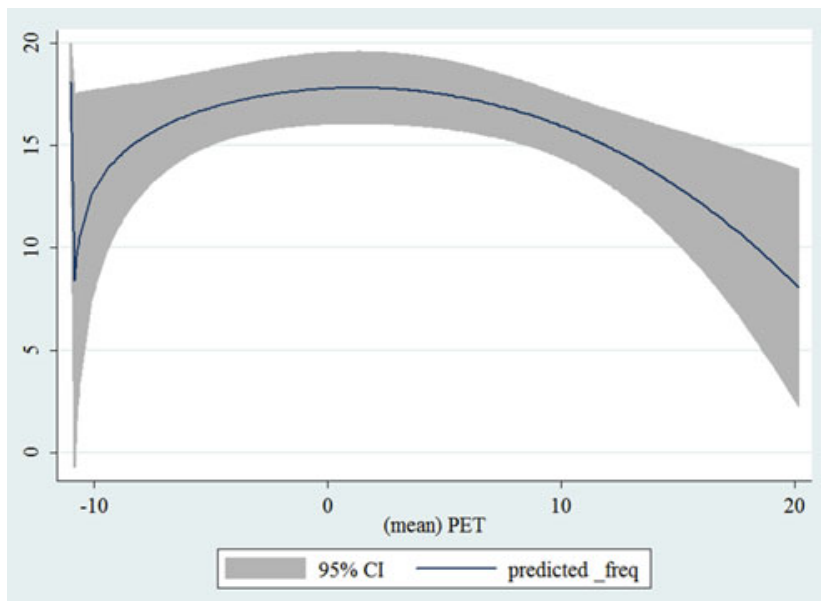

Fig. 11 Relationship of PETs and admissions of I44-Atrioventricular and left bundle-branch block

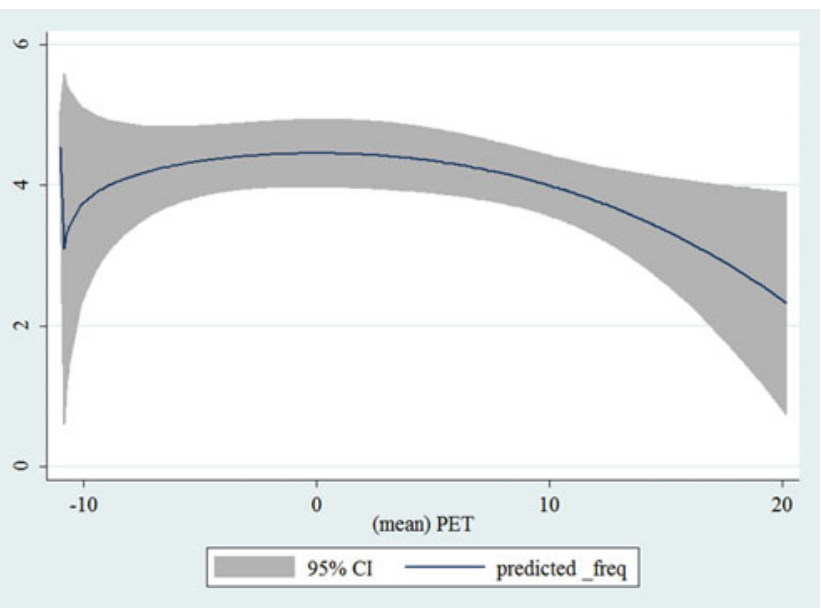

Fig. 12 Relationship of PETs and admissions of I45 - Other conduction disorders

relationship of the weather and cardiac arrhythmias is also very limited. In London, UK, in 1995-2003 (McGuinn et al. 2013), for every $1{ }^{\circ} \mathrm{C}$ decrease in ambient air temperature (meteorological data from all weather stations in southern England), risk of ventricular arrhythmias up to 7 days later increased by $1.2 \%(95 \% \mathrm{CI}-0.6 \%, 2.9 \%)$. In 32 top-ranked hospitals in Beijing, China, in 2006-2010 (Xu et al. 2013), there was no seasonal variation of cardiac arrhythmia admissions seen in young patients but excess admissions in winter were seen in older adults (relative risk 1.67, 95 \% CI 1.362.05).

\section{Weather and atrial fibrillation}

Literature on the relationship of the weather and atrial fibrillation could be slightly more than those described in the previous paragraphs. For example, in 43 centres in the province of Buenos Aires, Argentina, in 2004-2006

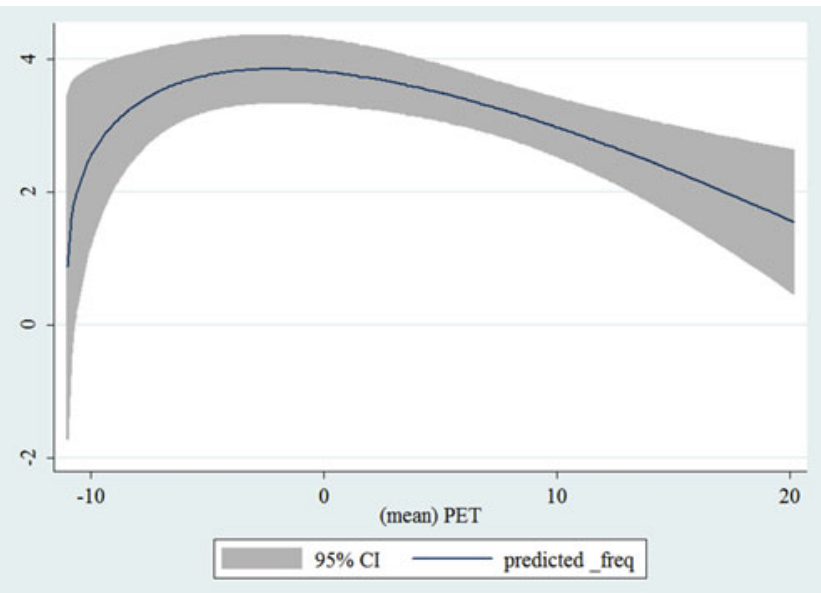

Fig. 13 Relationship of PETs and admissions of I46 - Cardiac arrest 


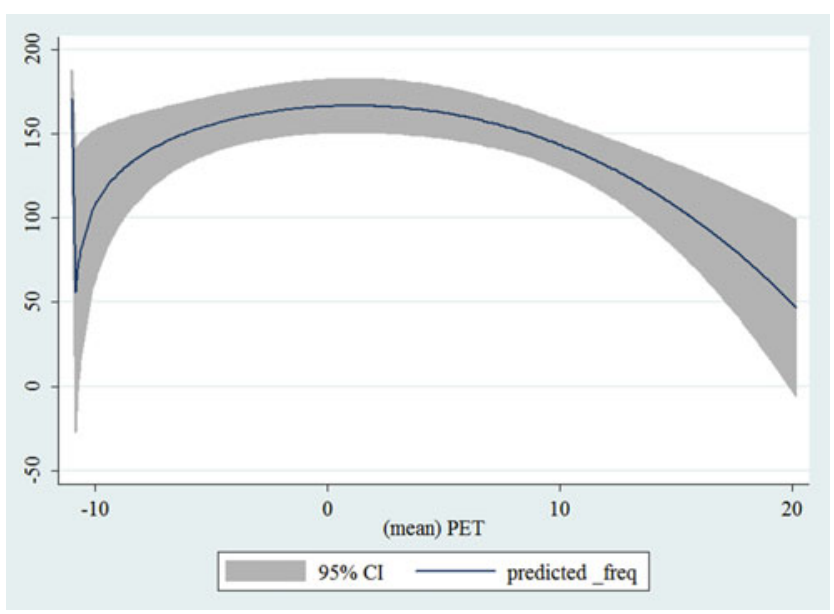

Fig. 14 Relationships of PETs and hospital admissions due to I48Atrial fibrillation and flutter

(Fustinoni et al. 2013), hospital admissions due to atrial fibrillation were found to peak between air temperatures 5 and $9{ }^{\circ} \mathrm{C}$. In a single Cardiac Care Unit located in Poland in 2005-2006 (Głuszak et al. 2008), the highest atrial fibrillation admissions were found in winter. Across Denmark, with half of the population in 1980-1993 (Frost et al. 2002), the risk of atrial fibrillation was modestly higher during the winter and was inversely associated with outdoor temperature. In a single hospital located in Toyoake, Japan, in 2001-2005 (Watanabe et al. 2007), admissions peaked in late autumn (relative risk 1.21, $95 \%$ CI 1.161.27) as well. Similar results were obtained across the USA in 2000-2008 (Deshmukh et al. 2013). In Ontario province, Canada, in 1988-2001 (Upshur et al. 2004), the peaks of atrial fibrillation admissions were in April, and the troughs were in August. These previous observations were consistent with the finding from the present study.

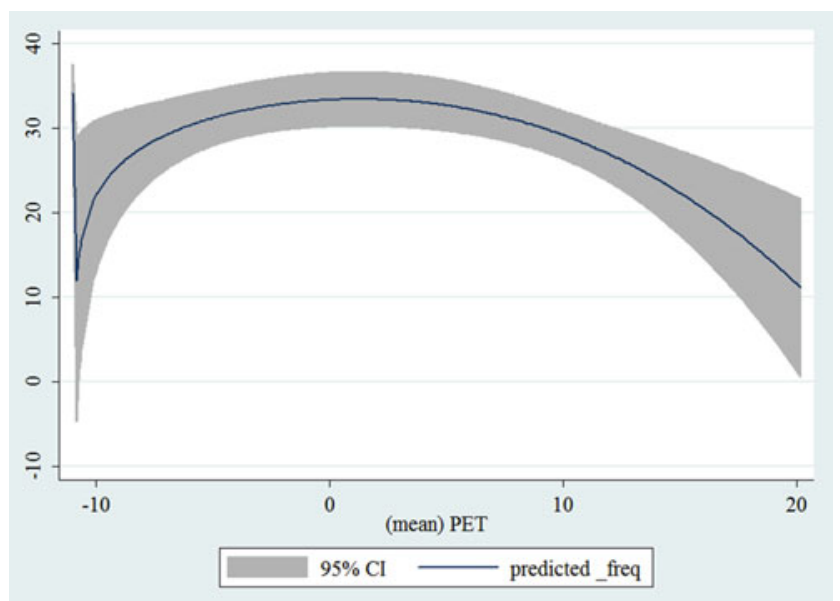

Fig. 15 Relationships of PETs and hospital admissions due to I49Other cardiac arrhythmias

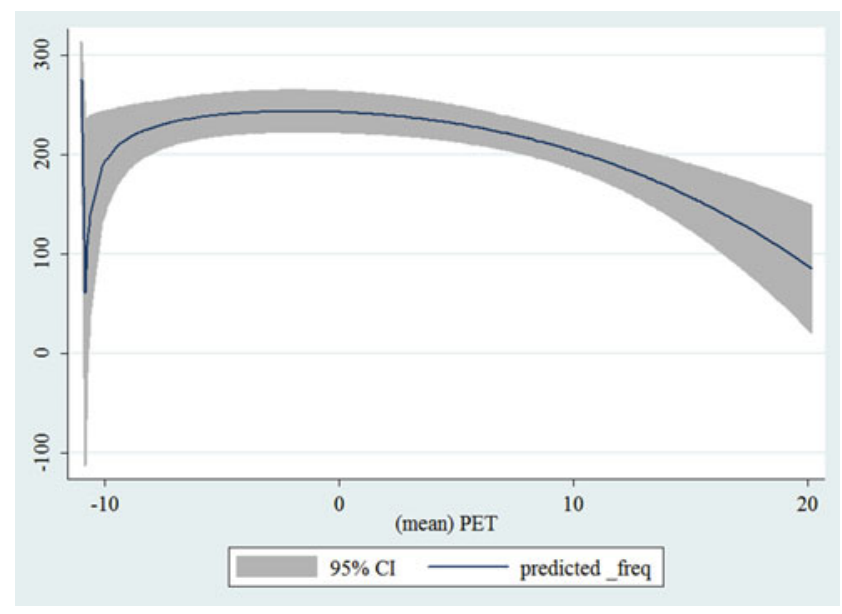

Fig. 16 Relationships of PETs and hospital admissions due to I50Heart failure

\section{Weather and heart failure}

Although literature on the relationship between the weather and heart failure seems to be slightly more than other subtypes of heart problems mentioned above as well, they were mostly with a focus on mortality. Here, we compared admission rates, incidence or prevalence only. In a single hospital in Tokyo, Japan, in 2004-2012 (Kaneko et al. 2014), admissions were observed to peak in winter and patients could be at a more vulnerable state. In a small teaching hospital in Urbana, USA, in 1997-2009 (Steinberg et al. 2012), heart failure admissions were found to occur more in September, October and November. Similar results were obtained in Ferrara Hospital located in Italy in 2002-2009 (Gallerani et al. 2011), and the authors also found that the effect was dependent on other known risk factors. In Niteroi, Brazil, in 1996-2004 (Jorge et al. 2009), the peak season for heart failure seemed to be late autumn. In

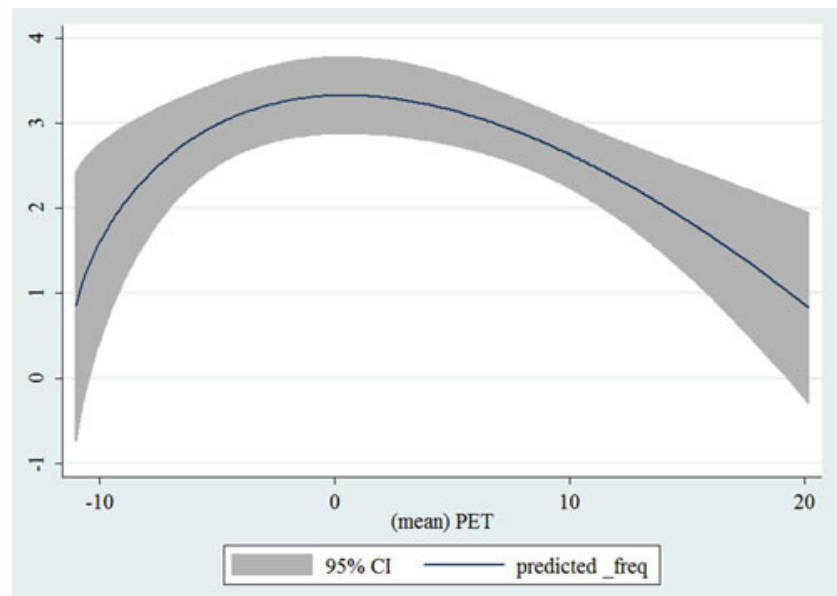

Fig. 17 Relationships of PETs and hospital admissions due to I51Complications and ill-defined descriptions of heart disease 
the University of Uyo Hospital located in Southeastern Nigeria in 1998-2001 (Ansa et al. 2008), excess admissions due to heart failure were also recorded in the rainy season when the cold days came. In all hospitals within the Ninohe district, Japan, in 2002-2005 (Ogawa et al. 2007), however, more heart failure admissions were found to be in spring and winter.

\section{Strengths and limitations}

The current study has a few strengths. First, our study is the first in assessing weather as biometeorological and hospital admissions due to other forms of heart disease by subtypes that have combined epidemiological, geographical and meteorological methods in Germany. Second, our data are limited to very recent years to ensure that we do not find significant statistical associations by chance alone through pooling decades of data. Third, we have drawn clear study catchments across Germany to ensure that both medical data and meteorological data can be matched geographically to rule out the potential ecological bias (i.e. one weather station plus numerous hospitals from other sub-regions). To be specific, in the current analysis, we ensured that in each German state, there could be at least one weather station to provide valid weather data to be correlated with hospital admissions within the state.

There were still other limitations worthy of being noted. First, we were unable to link with other population surveys to have adjusted covariates on lifestyle. In other words, this present study is at the ecological scale but not individual. Therefore, no causation could be drawn. By examining the correlations between the weather as biometeorological and hospital admissions, it is to indicate how much additional medical and social resources, such as medical professional time and hospital facilities (Shiue and Matzarakis 2011), might be anticipated with different days or seasons based on different PET values. Second, due to the restriction of the German law, we were only able to examine at the state level but not within smaller geographic regions. The lack of complete weather data in three German states has made our statistical analysis not perfectly complete at the national level. From the meteorological point of view, when investigating the weather effect, it would make scientific sense to generate climatic variables into a single index since they interact with each other at the same time and $1{ }^{\circ} \mathrm{C}$ in a cold climate would mean differently in a warm climate. Although there are other indexes such as Universal Thermal Climate Index (UTCI), the difference between UTCI and PET was not much (Shiue et al. 2014). In the current analysis, we did not include air pollution data due in part to the fact that by adjusting for air pollution in the epidemiological and statistical modelling, the effects could be stronger and easily reach statistical significance (Sabetghadam and AhmadiGivi 2014). The other practical reason was that the level of air pollution in Germany has been low in the recent years (more details via http://www.umweltbundesamt.de/en/data/ current-concentrations-of-air-pollutants-in-germany). Therefore, the effect from air pollution would be minimal. There could also be indexes to be developed in the future that could additionally incorporate air pollutants since they could influence each other at the same time as well. However, this might be methodologically difficult since the level of each pollutant could vary across each geographic region. Clinically, in Germany, the waiting time between making appointments and actual admissions, if not emergency, could vary from days to months depending on specialization. However, such information was not available within the current dataset. Consequently, any lag effect of the weather was not available to be analysed in the present study. Future research with novel approaches to keep the strengths and to overcome the limitations would be highly suggested.

\section{Research, practice and policy implications}

In sum, more hospital admissions due to other forms of heart disease by subtypes were observed on days with lower PET across Germany, although the causality cannot be confirmed due to the ecological study design in nature. However, nationally, how to prepare reallocation of medical and social resources in response to adapting to the change of weather, in particular at PET $<10^{\circ} \mathrm{C}$, would seem to be important. Previously, in the 2000s, one fourth of all Germans were found to believe that weather could influence their health to a "high degree" while one third were found to believe that weather could have "some influence on their health" (Höppe et al. 2002). In practice, the consideration of including the attitude from the general public and adaptation strategies in future public health programmes in order to save human capital in this country when facing climate change in the next decades would be suggested. For the future research direction, longitudinal monitoring on both the weather condition (with all meteorological parameters combined) and hospital admissions through observational or experimental study designs would be needed as well.

Acknowledgments Ivy Shiue was supported by the EU FP-7 project, Data without Boundaries (grant number no. 262608). The authors would also like to thank Rafael Beier and other German colleagues at Statistisches Bundesamt for their professional assistance in coordinating and checking data and hosting the research visit for the purpose of data analysis.

Compliance with ethical standards This study was approved and supported by the EU FP-7 Data without Boundaries project (grant number 262608; more details via http://www.dwbproject.org/) and Statistisches Bundesamt, Germany. Since this study is only a secondary data analysis, no other ethics approval was required.

Conflict of interest The authors declare that they have no competing interests. 
Open Access This article is distributed under the terms of the Creative Commons Attribution 4.0 International License (http:// creativecommons.org/licenses/by/4.0/), which permits unrestricted use, distribution, and reproduction in any medium, provided you give appropriate credit to the original author(s) and the source, provide a link to the Creative Commons license, and indicate if changes were made.

\section{References}

Ansa VO, Ekott JU, Essien IO, Bassey EO (2008) Seasonal variation in admission for heart failure, hypertension and stroke in Uyo. South East Nigeria Ann Afr Med 7:62-66

Ansari A, Burch GE (1969) Influence of hot environments on the cardiovascular system: a clinical study of 23 cardiac patients at rest. Arch Intern Med 123:371-378

Bean WB, Mills CA (1938) Coronary occlusion, heart failure, and environmental temperatures. Am Heart J 16:701-713

Bhaskaran K, Hajat S, Haines A, Herrett E, Wilkinson P, Smeeth L (2009) Effects of ambient temperature on the incidence of myocardial infarction. Heart 95:1760-1769

Chen SJ, Chao TF, Lin YJ, Lo LW, Hu YF, Tuan TC, Hsu TL, Yu WC, Leu HB, Chang SL, Chen SA (2012) Cool seasons are related to poor prognosis in patients with infective endocarditis. Int $\mathrm{J}$ Biometeorol 56:973-981

Deshmukh AJ, Pant S, Kumar G, Hayes K, Badheka AO, Dabhadkar KC, Paydak H (2013) Seasonal variations in atrial fibrillation related hospitalizations. Int J Cardiol 168:1555-1556

Epstein SE, Stampfer M, Beiser D, Goldstein RE, Braunwald E (1969) Effects of a reduction in environmental temperature on the circulatory response to exercise in man-implications concerning angina pectoris. N Engl J Med 280:7-11

Finkelhor RS, Cater G, Qureshi A, Einstadter D, Hecker MT, Bosich G (2005) Seasonal diagnosis of echocardiographically demonstrated endocarditis. Chest 128:2588-9252

Frost L, Johnsen SP, Pedersen L, Husted S, Engholm G, Sørensen HT, Rothman KJ (2002) Seasonal variation in hospital discharge diagnosis of atrial fibrillation: a population-based study. Epidemiology $13: 211-215$

Fustinoni O, Saposnik G, Esnaola y Rojas MM, Lakkis SG, Sposato LA, ReNACer Investigators (2013) Higher frequency of atrial fibrillation linked to colder seasons and air temperature on the day of ischemic stroke onset. J Stroke Cerebrovasc Dis 22:476-481

Gallerani M, Boari B, Manfredini F, Manfredini R (2011) Seasonal variation in heart failure hospitalization. Clin Cardiol 34:389-394

Głuszak A, Kocoń S, Zuk K, Aljabali P, Gluza A, Siwek K (2008) Episodes of atrial fibrillation and meteorological conditions. Kardiol Pol 66:958-963

Hanna JM (1999) Climate, altitude, and blood pressure. Hum Biol 71:553

Herlitz J, Eek M, Holmberg M, Holmberg S (2002) Diurnal, weekly and seasonal rhythm of out of hospital cardiac arrest in Sweden. Resuscitation 54:133-138

Highman B, Altland PD (1962) Effect of exposure and acclimatization to cold on susceptibility of rats to bacterial endocarditis. Proc Soc Exp Biol Med 110:663-667

Höppe P (1999) The physiological equivalent temperature - a universal index for the biometeorological assessment of the thermal environment. Int J Biometeorol 43:71-75

Höppe P, von Mackensen S, Nowak D, Piel E (2002) Prevalence of weather sensitivity in Germany. Dtsch Med Wochenschr 127:15-20

Jorge JE, Cagy M, Mesquita ET, Costa TL, Moscavitch SD, Rosa ML (2009) Seasonal variation in hospitalizations due to heart failure in Niterói city. South Brazil Rev Saude Publ 43:555557

Kaneko H, Suzuki S, Goto M, Arita T, Yuzawa Y, Yagi N, Murata N, Yajima J, Oikawa Y, Sagara K, Otsuka T, Matsuno S, Kano H, Uejima T, Nagashima K, Kirigaya H, Sawada H, Aizawa T, Yamashita T (2014) Presentations and outcomes of patients with acute decompensated heart failure admitted in the winter season. J Cardiol. doi:10.1016/j.jjcc.2014.03.004

Liu IF, Chang SL, Lo LW, Hu YF, Tuan TC, Kong CW, Wu TJ, Chiang CE, Chen SA, Lin YJ (2011) Relationship between temperature change and the requirement for a permanent pacemaker implantation in bradyarrhythmias. Int J Biometeorol 55:733-739

Matzarakis A, Mayer H (1996) Another kind of environmental stress: thermal stress. WHO Newslett 18:7-10

McGuinn L, Hajat S, Wilkinson P, Armstrong B, Anderson HR, Monk V, Harrison R (2013) Ambient temperature and activation of implantable cardioverter defibrillators. Int J Biometeorol 57:655-662

Milo-Cotter O, Setter I, Uriel N, Kaluski E, Vered Z, Golik A, Cotter G. (2006) The daily incidence of acute heart failure is correlated with low minimal night temperature: cold immersion pulmonary edema revisited? J Card Fail 12(2):114-9

Modesti PA (2013) Season, temperature and blood pressure: a complex interaction. Eur J Intern Med 24:604-607

Ogawa M, Tanaka F, Onoda T, Ohsawa M, Itai K, Sakai T, Okayama A, Nakamura M, Northern Iwate Heart Disease Registry Consortium (2007) A community based epidemiological and clinical study of hospitalization of patients with congestive heart failure in Northern Iwate, Japan. Circ J 71:455-459

Sabetghadam S, Ahmadi-Givi F (2014) Relationship of extinction coefficient, air pollution, and meteorological parameters in an urban area during 2007 to 2009. Environ Sci Pollut Res Int 21:538-547

Shiue I, Matzarakis A (2011) When stroke epidemiology meets weather and climate: a heat exposure index from human biometeorology. Int J Stroke 6:176

Shiue I, Muthers S, Bearman N (2014) The role of cold stress in predicting extra cardiovascular and respiratory admissions. Int $\mathrm{J}$ Cardiol 172:e109-e110

Steinberg GR Jr, Byron JK, Mahoney MM (2012) A retrospective study of circadian and seasonal presentations of dogs with congestive heart failure: 119 cases (1997-2009). J Vet Emerg Crit Care (San Antonio) 22:341-346

Stratil P, Wallmueller C, Schober A, Stoeckl M, Hoerburger D, Weiser C, Testori C, Krizanac D, Spiel A, Uray T, Sterz F, Haugk M (2013) Seasonal variability and influence of outdoor temperature on body temperature of cardiac arrest victims. Resuscitation 84:630-634

Tanigawa-Sugihara K, Iwami T, Nishiyama C, Kitamura T, Goto M, Ando M, Nishiuchi T, Hayashi Y, Kawamura T (2013) Association between atmospheric conditions and occurrence of out-of-hospital cardiac arrest-10-year population-based survey in Osaka. Circ J 77:2073-2078

Upshur RE, Moineddin R, Crighton EJ, Mamdani M (2004) Is there a clinically significant seasonal component to hospital admissions for atrial fibrillation? BMC Health Serv Res 4:5

Watanabe E, Kuno Y, Takasuga H, Tong M, Sobue Y, Uchiyama T, Kodama I, Hishida H (2007) Seasonal variation in paroxysmal atrial fibrillation documented by 24-hour Holter electrocardiogram. Heart Rhythm 4:27-31

World Health Organisation (WHO) (2009) International classification of diseases (ICD) version 10. http://apps.who.int/classifications/apps/ icd/icd10online/ Accessed 1 Jul 2014

Xu B, Liu H, Su N, Kong G, Bao X, Li J, Wang J, Li Y, Ma X, Zhang J, Yu GP, Zhao L (2013) Association between winter season and risk of death from cardiovascular diseases: a study in more than half a million inpatients in Beijing. China BMC Cardiovasc Disord 13:93 